\title{
OPINIÃO DE MULHERES SOBRE A PARTICIPAÇÃO DO PAI NO ALEITAMENTO MATERNO
}

\author{
Lucimare Ferraz ${ }^{1}$ \\ Patricia Pereira de Oliveira ${ }^{2}$ \\ Marinez Amabile Antoniolli ${ }^{3}$ \\ Alcimara Benedett ${ }^{4}$ \\ Vanessa Bossetti ${ }^{5}$ \\ Kaliandra de Almeida ${ }^{6}$
}

FERRAZ, L.; OLIVEIRA, P. P. de; ANTONIOLLI, M. A.; BENEDETT, A.; BOSSETTI, V.; ALMEIDA, K. de. Opinião de mulheres sobre a participação do pai no aleitamento materno. Arq. Cienc. Saúde UNIPAR, Umuarama, v. 20, n. 2, p, 95-99, maio/ago. 2016.

\begin{abstract}
RESUMO: Esta pesquisa teve o objetivo de conhecer a participação do pai no processo de aleitamento materno, segundo as puérperas. Trata-se de um estudo descritivo-exploratório, em que participaram 115 mulheres com filhos de dois a oito meses de idade. Os resultados foram obtidos por meio de entrevistas semiestruturadas. A análise dos dados foi realizada com a aplicação do software Statistical Package for Social Sciences (SPSS) versão 19. A pesquisa foi aprovada pelo Comitê de Ética. Como resultados, evidenciou-se que o pai exerce influência no aleitamento materno e sua ajuda facilita o processo de amamentar. Além disso, as mulheres reconhecem a importância do pai como um auxiliador e incentivador. Sendo que, segundo as mulheres, quanto maior o apoio dos pais, maiores as chances de sucesso no aleitamento. Desse modo, a participação paterna nesse momento deve ser incentivada.
\end{abstract}

PALAVRAS-CHAVE: Aleitamento materno. Paternidade. Relações Familiares.

\section{VIEW OF WOMEN ABOUT THE PARTICIPATION OF THE FATHER IN BREASTFEEDING}

\begin{abstract}
This research aimed to learn about the participation of fathers in the breastfeeding process, according to the mothers who are breastfeeding. This is a descriptive exploratory study, developed with the participation of one hundred and fifteen women with children from two to eight months old. Results were obtained by the use of structured interviews. Data analysis was performed by using the Statistical Package for Social Sciences (SPSS) software, version nineteen. The study was approved by the Ethics Committee. As a result, it was found that the father has influence on breastfeeding and his help makes the breastfeeding process easier. Moreover, women recognize the father's importance as a helper and supporter. According to the women, the more fathers support the process, the greater the chances of success in breastfeeding. Thereby, the father's involvement at this time should be encouraged.

KEYWORD: Breastfeeding. Family Relations. Paternity.
\end{abstract}

\section{Introdução}

Amamentar é um processo que envolve interação profunda entre mãe e filho, repercutindo no estado nutricional, na habilidade de se defender de infecções, no desenvolvimento cognitivo e emocional da criança; com implicações também na saúde física e psíquica da mãe (BRASIL, 2009).

Segundo Silveira e Lamounier (2006), ao longo do século XX a prevalência e a duração da amamentação diminuíram, chegando a atingir altos índices de mortalidade infantil, principalmente na década de 70. Entre os fatores influenciadores dessa situação está a crescente inserção da mulher no mercado de trabalho e a produção do leite industrializado, aliados a falta de informações sobre os benefícios do aleitamento para a população em geral.

A partir de 1980, a Organização Mundial da Saúde efetivou as campanhas que resultaram em um movimento a favor da valorização da amamentação, especialmente a exclusiva nos primeiros meses de vida. Um dos elementos desse movimento foi a divulgação de dados científicos, sobre os prejuízos que a suplementação ou substituição do leite ma- terno pode provocar à saúde da criança (GIUGLIANI, 2010). Atualmente, o aleitamento materno cada vez mais se mostra fundamental para o desenvolvimento saudável das crianças, pois trata-se do alimento mais completo que se pode oferecer ao recém-nascido, sendo capaz de suprir as necessidades nutricionais, imunológicas e psicológicas da criança. É o único alimento que impactou positivamente as taxas de mortalidade infantil, devido a seu mecanismo de transferência dos anticorpos da mãe para a criança. Os benefícios que o aleitamento materno pode garantir tanto para mãe quanto para a criança são inúmeros. Naturalmente pode-se pensar que todas as mulheres têm condição plena para exercer a amamentação, no entanto a mesma está cercada de inúmeras questões socioeconômicas culturais, que podem influenciar neste processo de aleitamento materno (SOUZA, 2014).

Sendo a amamentação fortemente influenciada pelo meio em que a puérpera está inserida, para que essa prática seja bem-sucedida a mãe necessita de constante incentivo. Não basta que a mãe opte pelo aleitamento materno, é necessário que esta mãe esteja inserida em um ambiente que a apoie na sua opção, sendo que os pais têm sido identificados

DOI: https://doi.org/10.25110/arqsaude.v20i2.2016.4674

${ }^{1}$ Enfermeira. Doutora em Ciências da Saúde pela UNIFESP. Docente do Programa Stricto Sensu em Ciências da Saúde da Unochapeco e do departamento de Enfermagem da UDESC.

${ }^{2}$ Médica. Doutora em Ciências com ênfase na área de Saúde da Criança e da Mulher pelo IFF/Fundação Oswaldo Cruz. Docente da Área de Ciências da Saúde da Unochapeco.

${ }^{3}$ Farmacêutica. Mestre em Ciência dos Alimentos pela Universidade Federal de Santa Catarina. Docente da Área de Ciências da Saúde da Unochapeco. ${ }^{4}$ Enfermeira. Doutora em Enfermagem pela Universidade de São Paulo.

${ }^{5}$ Graduanda em Farmácia pela Universidade Comunitária da Região de Chapecó (Unochapecó).

${ }^{6}$ Graduanda em Medicina pela Universidade Comunitária da Região de Chapecó (Unochapecó).

Endereço dos autores: Av. Senador Attílio Fontana, 591-E, Bairro: Efapi. Chapecó, SC. Cep: 89809-000. Caixa Postal: 1141. 
como importante fonte de apoio nesse período (BRASIL, 2009).

O aleitamento materno tem sido considerado pela sociedade como responsabilidade da mulher, entretanto é reconhecida a relevância da presença e participação do pai da criança durante esse processo (PIAZZALUNGA; LAMOUNIER, 2009). De acordo com Pontes, Alexandriano e Osório, tem-se o paradigma de que o homem não faz parte desse processo, e que "o monopólio materno, uma defesa cultural, pode trazer dificuldades ao homem para participar do amamentar" (p.404), e que neste período os pais sentem-se deslocados e excluídos da prática do aleitamento.

Sanches (2010) relata a existência de fatores críticos que podem interferir na prática da amamentação, como a presença do companheiro. "O pai não é um simples incentivador da prática do aleitamento materno, mas sim o principal influenciador da amamentação" (PIAZZALUNGA; LAMOUNIER, 2009 p. 56).

De acordo com estudo realizado por Buchala e Moraes (2005), o medo, depressão, tensão, dor, fadiga e ansiedade tendem a provocar o fracasso da amamentação, contudo a calma, confiança, tranquilidade e o apoio da rede social que envolve a mãe são aspectos favorecedores do processo de aleitamento.

Em todo período gravídico-puerperal é necessário que a mulher receba apoio familiar, pois naturalmente torna-se mais frágil e vulnerável ao estresse do seu novo cotidiano; sendo extremamente importante neste processo o apoio do companheiro, pois enquanto pai deve participar da saúde integral da mulher e do seu filho. $\mathrm{O}$ apoio paterno é primordial para manutenção da amamentação materna. A participação paterna neste processo é rodeada de sentimentos paradoxais, pois os pais ao mesmo tempo em que sentem-se felizes, encorajados a contribuir neste processo, sentem-se inúteis, excluídos e acabam frustrados (SILVIA; SANTIAGO; LAMONIER, 2012). Partindo desses pressupostos realizamos uma pesquisa com o objetivo de conhecer a participação do pai no processo de aleitamento materno, segundo as puérperas.

\section{Metodologia}

Trata-se de um estudo descritivo, exploratório e quantitativo. Foram incluídas no estudo as mães que tinham idade igual ou superior a 16 anos, que tinham filhos que estavam com dois a oito meses de idade, e estavam ainda amamentando. As mães participantes da pesquisa foram selecionadas através da carteirinha de vacinação das crianças em quatro Centros de Saúde. Esses Centros de Saúde foram definidos por meio de sorteio, sendo um em cada região dos Núcleos de Apoio a Saúde da Família-NASF (Sul, Norte, Leste e Oeste) da rede de saúde do município de Chapecó, SC.

Fizeram parte do estudo 115 mulheres, as quais foram entrevistadas em seu domicílio. Utilizou-se um roteiro de perguntas semiestruturadas e auto-elaboradas. As entrevistas ocorreram no período de outubro de 2011 a março de 2012. A análise descritiva dos dados coletados foi realizada com a aplicação do software Statistical Package for Social Sciences (SPSS) versão 19.

$\mathrm{Na}$ abordagem às puérperas foi-lhes explicado o propósito, o objetivo e os procedimentos da pesquisa, além de solicitado a assinatura de um termo de consentimento li- vre e esclarecido.

A pesquisa foi realizada após a aprovação do Comitê de Ética em Pesquisa da Universidade Comunitária da Região de Chapecó sob protocolo n ${ }^{\circ} 138 / 11$ de 10 de agosto de 2011 e Secretaria Municipal de Saúde de Chapecó-SC. Os protocolos usados na pesquisa estavam de acordo com a Resolução 10/196/96, Cap. VI, VI-5, do Conselho Nacional de Saúde/Ministério da Saúde.

\section{Resultados e Discussão}

Foram selecionadas 116 mulheres para participarem da pesquisa, porém uma mãe não aceitou participar. Sendo assim, obteve-se a participação de 115 mulheres puérperas nessa pesquisa. Destas, $92,2 \%$ moram com o pai de seu filho lactente.

Para Silveira e Lamonier (2006), o fato de o pai residir com a criança e com a mãe está associada com a sua influência na decisão de amamentar e na duração do aleitamento. No estudo realizado por Carrascoza (2005) houve uma diferença estatística significativa entre o estado civil das puérperas e desmame precoce, pois o pesquisador observou um maior percentual de desmame precoce por parte das mães solteiras, enquanto um aleitamento materno mais prolongado por parte das mães casadas, sugerindo dessa maneira que quanto maior a estabilidade conjugal, menores as chances de desmame precoce.

Igualmente, o conhecimento sobre o aleitamento materno leva o pai a desempenhar maior influência sobre a vontade da mãe de amamentar (PIAZZALUNGA; LAMOUNIER, 2009).

Em relação à opinião que as mulheres acreditam que seu companheiro tem sobre o aleitamento materno, $64,1 \%$ percebem que o pai considera o leite materno o alimento ideal para a criança. Além disso, 51,9\% das puérperas supõem que os pais acreditam que o leite materno também previne doenças. Somente $15,1 \%$ delas, percebem que o pai/companheiro reconhece os benefícios da amamentação para a mãe.

Os resultados apresentados demonstram que os pais consideram o leite materno o alimento ideal para a criança, e é um fator importante na prevenção de doença, evidenciando que os pais (re)conhecem os benefícios do aleitamento materno. $\mathrm{O}$ conhecimento em relação aos benefícios do aleitamento materno pelos pais/companheiros pode ser um dos fatores que favorecem a escolha e a manutenção dessa prática (PONTES; ALEXANDRINO; OSÓRIO, 2008).

A percepção das mulheres do estudo quanto à importância do aleitamento materno para as crianças, condiz com achados do estudo realizado por Barreira e Machado (2004), em que o leite materno é percebido pelos pais como um elemento benéfico e imprescindível à saúde da criança, particularmente nos primeiros meses de vida, revelando que os familiares têm informação de que o leite materno se configura como fonte de promoção à saúde e prevenção às doenças. Consoante a isso, o fato de os familiares perceberem os benefícios da amamentação predispõe ao seu incentivo pela relação direta que esta tem com a saúde da criança.

Em outra pesquisa, realizada por Silva (et al, 2012), quase totalidade dos pais $(95,4 \%)$ apresentou opinião favorável à amamentação. As principais razões apontadas pelos pais, segundo as mães, para que seus bebês mamassem fo- 
ram: o leite materno é o melhor para a saúde do bebê $(53,8 \%)$, é o alimento ideal $(16,2 \%)$ e é bom para o desenvolvimento infantil $(10,0 \%)$.

Com relação aos benefícios da amamentação para a mãe, somente $14 \%$ puérperas acreditam que os seus companheiros reconhecem os benefícios da amamentação para a saúde das mesmas. Na pesquisa realizada por Pontes e colaboradores (2009), evidenciou-se que o conhecimento dos pais sobre o leite materno e amamentação está centrado na criança, e que dos 115 pais apenas três tentaram dizer algo sobre as vantagens para a mulher. Essa falta de enfoque por parte dos pais para a saúde da mulher pode desestimulá-la na continuidade do amamentar (PONTES; ALEXANDRINO; OSÓRIO, 2008).

Em estudo realizado por Barreira e Machado (2004), também foi percebida significativa dificuldade por parte das familiares em tentar enumerar os benefícios do aleitamento materno para a puérpera. Essa situação se deve, provavelmente, ao fato de durante o pré-natal existir uma tendência focal dos profissionais de saúde em enfatizar apenas os benefícios relacionados à saúde da criança.

Quanto mais o pai souber das vantagens e do manejo da amamentação, maior será a sua participação nesse processo e, consequentemente, maior será a prevalência do aleitamento, isso porque o pai pode proporcionar segurança e tranquilidade à mãe nesse momento que ela está fragilizada física e emocionalmente (LANA, 2001). A forte influência exercida pelo companheiro ocorre por ele acreditar que o leite materno é o melhor alimento para a criança (COSTA, 2005).

Outro aspecto importante encontrado neste estudo é a referência que as mulheres fazem ao fato de seus companheiros (pais de seus filhos) considerarem o baixo custo financeiro do leite materno. $\mathrm{O}$ fato de o leite materno não ter custos traz vantagens para a família, para o sistema de saúde e a sociedade em geral, já que se reduz o gasto com leites artificiais, mamadeiras e possíveis doenças que possam ser adquiridas pelas crianças que não dispõem da proteção que o aleitamento materno proporciona (GIUGLIANI, 2010). Além disso, Piazzalunga e Lamounier (2011) enfatizam que a amamentação ao proteger as crianças contra doenças, diminui os gastos diretos e indiretos no âmbito da assistência à saúde.

Em relação à participação do pai no processo de aleitamento materno, $17 \%$ das puérperas não consideram essa participação importante, mas para $83 \%$ a participação do pai nesse período é importante. Sendo que para 70,8\% sem essa ajuda/participação seria muito difícil amamentar. Segundo Pinto (2008), atualmente a participação do pai é vista pela mãe como algo importante e desejável porque alivia a sobrecarga que a amamentação acarreta. A postura do pai como parceiro na prática da amamentação parece ser determinante para o seu sucesso e para a satisfação do casal.

Foi identificado no nosso estudo que a participação do pai no processo de aleitamento materno dá-se na forma de ajuda à mulher. Esses resultados estão apresentados na tabela 1 .
Tabela 1: Participação do pai no processo do aleitamento materno, na ótica das mulheres puérperas, Chapecó-SC, 2012.

\begin{tabular}{|c|c|c|}
\hline O pai ajuda & $\mathrm{N}^{\mathrm{o}}$ & $\%$ \\
\hline $\operatorname{Sim}$ & 92 & 80 \\
\hline Não & 23 & 20 \\
\hline \multicolumn{3}{|l|}{ Tipo de ajuda } \\
\hline O pai ajuda a cuidar da puérpera e do bebê & 73 & 79,3 \\
\hline $\begin{array}{l}\text { O pai do bebê ajuda a puérpera nos serviços } \\
\text { da casa }\end{array}$ & 53 & 57,6 \\
\hline O pai ajuda cuidando dos outros filhos & 27 & 29,3 \\
\hline
\end{tabular}

Os dados da tabela 1 demonstram que a maioria dos pais auxilia a puérpera no processo da amamentação. Entre os pais que ajudam a puérpera, estes desempenham seu papel não apenas no cuidado com a criança recém-nascida, mas também no cuidado com a própria puérpera. A concepção da participação mais efetiva dos homens no cotidiano familiar, particularmente no cuidado com o bebê, vem sendo vinculada com a "nova paternidade", em que há maior participação paterna em todos os aspectos de cuidados com a criança (PIAZZALUNGA; LAMOUNIER, 2009 p. 50).

O estudo realizado por Machado e Bosi (2008) identificou que a presença do companheiro é reconhecida como suporte valioso no processo de amamentação, especialmente quando existe uma participação mais efetiva nos cuidados diários com a companheira e a criança. Nesse caso, o pai acaba por ter papel significativamente positivo de apoio ao aleitamento materno, sendo também corresponsável por essa prática.

Outras ajudas também foram citadas pelas puérperas do estudo que realizamos e estão relacionadas aos serviços da casa e ao cuidado com os outros filhos. Sobre isso Piazzalunga e Lamounier (2011) verificaram em seu estudo que muitos pais se fazem presente na fase de amamentação oferecendo atenção a esposa e ao filho, por meio da divisão das tarefas domésticas, ajudando a posicionar a criança no seio materno e nos cuidados com os filhos anteriores e atuais. Os autores destacam ainda que "homem-pai está mudando suas atitudes e sua percepção sobre a mulher em relação à amamentação, passando a respeitá-la e apoiá-la nesse período" (p. 138).

No período da amamentação é difícil para a mulher cuidar do bebê, da casa, do marido e de outros filhos sozinha. Por isso, é importante que a família se faça presente e ajude a puérpera nas tarefas de casa para que ela possa se dedicar ao recém-nascido (BRASIL, 2007). A chegada de uma criança traz muitas alegrias para toda a família, porém o casal necessita repensar e reelaborar suas atividades domésticas (PIAZZALUNGA, 2009).

Quando questionadas se o processo do aleitamento materno interferiu no seu relacionamento com o pai da criança, 92,4\% das puérperas responderam que não. Entre as 7,6\% das puérperas que mencionaram haver mudança, 58,3\% relataram que o aleitamento materno aumentou o contato íntimo e os gestos de afeto e 41,7\% fizeram menção contrária a esse aspecto, afirmando que no processo de amamentar diminuiu o contato íntimo e os gestos de afeto entre o casal.

Brito e Oliveira (2006) identificaram em seu estudo 
o afastamento físico, emocional e sexual por parte da companheira durante a fase de aleitamento materno, porém as alterações ocorridas no relacionamento não foram consideradas por eles como algo negativo em suas vidas. Para os autores, a diminuição do interesse e do desejo sexual entre os cônjuges tem raízes históricas na separação que se faz entre a maternidade e o sexo.

Comparando com o período anterior a gestação, o interesse sexual feminino é reduzido na maior parte dos casos por até três a quatro meses após o parto, isso ocorre por fatores fisiológicos; mas após o terceiro mês ou depois que a amamentação cessou, as mudanças orgânicas regridem (PAMPLONA; MELO-DE-AGUIAR, 2010).

Diante disso, Piazzalunga e Lamounier (2011, p.140), ressaltam que "é necessário incluir o pai, orientando-o e encorajando-o a participar ativamente nas tarefas de apoio à esposa e de cuidador do filho, desde o pré-natal, na primeira infância e ao longo do seu desenvolvimento". Do mesmo modo, faz-se necessário refletir sobre a formação dos profissionais de saúde, pois de acordo com Silva, Santiago e Lamonier (2012), durante a formação acadêmica os temas abordados sobre aleitamento materno ainda condizem com o manejo técnico da amamentação e sobre as propriedades e benefícios do leite materno, marginalizando os demais aspectos da determinação social da amamentação, a exemplo da participação do pai nesse processo. Outrossim, os profissionais que atuam nos serviços de saúde não têm capacitações para receber e assistir os pais no período do pré-natal e do puerpério, situação essa que deve ser (re)pensada nas políticas de educação permanente e continuada nos serviços de saúde.

\section{Considerações Finais}

Por fim, evidencia-se que o pai exerce influência no aleitamento materno, pois sem a ajuda do companheiro se torna mais difícil o processo de amamentar para a mulher. Esse estudo mostrou dados que reforçam a ideia de que as puérperas reconhecem a importância do pai no processo de aleitamento materno, como auxiliares e incentivadores dessa prática, seja pelos cuidados dispensados à criança e à puérpera, ou pelos conhecimentos que os pais têm sobre a importância do aleitamento, fato este que pode influenciar na decisão da puérpera de amamentar. Entretanto, apesar das mulheres referirem que os companheiros conhecem os benefícios do leite materno, principalmente a saúde da criança, na ótica das mães, os pais pouco sabem sobre os benefícios da amamentação para a mulher. Nesse sentido, é importante que o pai (re)conheça os benefícios do leite materno também para a puérpera, já que este fato pode estimulá-la a amamentar.

Quanto mais o pai, a puérpera e a família souberem a respeito dos benefícios da amamentação para a saúde da criança e da mãe, e quanto maior o apoio que a puérpera receber nesse período, maiores serão as chances de que a prática do aleitamento materno seja vivenciada com sucesso. A promoção do aleitamento materno deve ser incentivada pelos profissionais de saúde, por meio de uma maior inserção e incentivo da participação paterna deste o pré-natal.

\section{Referências}

BARREIRA, S. M. C.; MACHADO, M. de F. A. S.

Amamentação compreendendo a influência do familiar.

Acta Scientiarum. Health Sciences, v. 26, n.1, p.11-20, 2004.

BRASIL. Ministério da Saúde. Secretaria de Atenção à Saúde. Promovendo o aleitamento materno. 2. ed. Brasília: 2007. Álbum seriado. 18 p.

Saúde da criança: nutrição infantil: aleitamento materno e alimentação complementar. Brasília: Ministério da Saúde, 2009. 112 p.

BRITO, R. S.; OLIVEIRA, E. M. F. de. Aleitamento materno: mudanças ocorridas na vida conjugal do pai. Ver. Gaúcha Enferm. v. 27, n. 2, p.193-202, 2006.

BUCHALA, L. M.; MORAES, M. S. Amamentação vivenciada com sucesso por um grupo de mulheres. Arq. Ciênc. Saúde, v.12, n. 4, p. 177-182, 2005.

CARRASCOZA, K. C.; COSTA JUNIOR, Á. L.;

MORAES, A. B. A. de. Fatores que influenciam o desmame precoce e a extensão do aleitamento materno. Estud. psicol. v. 22 , n. 4 , p. 433-440, 2005.

COSTA, C. R. dos. Participação do companheiro no processo do aleitamento materno. Nutrição em Pauta, v.13, n. 71, p. 31-35, 2005.

LANA, A. P. B. O livro de estímulo à amamentação: uma visão biológica, fisiológica e psicológica comportamental da amamentação. São Paulo: Atheneu, 2001.

MACHADO, M. M. T.; BOSI, M. L. M. Compreendendo a prática do aleitamento exclusivo: um estudo junto a lactantes usuárias da rede de serviços em Fortaleza, Ceará, Brasil. Rev. Bras. Saúde Mater. Infant. v. 8, n. 2, p. 187196, 2008.

PAMPLONA, V.; MELO-DE-AGUIAR, A. Aspectos psicossexuais na lactação. In: __ . Amamentação bases científicas. 3. ed. Rio de Janeiro: Guanabara Koogan, 2010. p. 182.

PIAZZALUNGA, C. S. dos; LAMOUNIER, J. A. A paternidade e sua influencia no aleitamento materno. Pediatria, v. 31, n. 1, p. 49-57, 2009.

O contexto atual do pai na amamentação uma abordagem qualitativa. Rev. Med. Minas Gerais, v. 21, n. 2, p. 133-141, 2011.

PINTO, T. V. Promoção, proteção e apoio ao aleitamento materno na comunidade. Revisão das estratégicas no período pré-natal e após a alta. ArquiMed. v. 22, n. 2-3, p. 57-68, 2008.

PONTES, C. M.; ALEXANDRINO, A. C.; OSÓRIO, 
M. M. Participação do pai no processo da amamentação: vivências, conhecimentos, comportamentos sentimentos eletrônicos . J. Pediatr. v. 84, n. 4, p. 357-364, 2008.

PONTES, C. M.; ALEXANDRINO, A. C.; OSORIO, M. M. O envolvimento paterno no processo da amamentação: propostas de incentivo. Rev. Bras. Saude Mater. Infant. v. 9, n. 4, p. 399-408, 2009.

PONTES, C. M.; ALEXANDRINO, A. C.; OSORIO, M. M. Participação do pai no processo da amamentação: vivências, conhecimentos, comportamentos e sentimentos. J. Pediatr. Rio de Janeiro, v. 84, n. 4, p. 357-364, ago. 2008.

SANCHES, M. T. C. Enfoque fonoaudiológico. In: Amamentação bases cientificas. 3. ed. Rio de Janeiro: Guanabara Koogan, 2010. p. 101.

SILVA, B. T.; SANTIAGO, L. B.; LAMONIER, J. A. Apoio paterno ao aleitamento materno: uma revisão integrativa. Rev. paul. pediatr. v. 30, n. 1, p. 122-130, 2012.

SILVA, P. P. da et al. A percepção das mães sobre o apoio paterno: influência na duração do aleitamento materno. Rev. Paul. Pediatr. v. 30, n. 3, p. 306-313, 2012.

SILVEIRA, F. J. F. da; LAMOUNIER, J. A. Fatores associados à duração do aleitamento materno em três municípios na região do Alto Jequitinhonha, Minas Gerais, Brasil. Cad. Saúde Pública, v. 22, n.1, p. 77, 2006.

SOUZA, A. B. G. Enfermagem neonatal cuidado integral ao recém-nascido. 2. ed. São Paulo: Atheneu, 2014. v. 1. $195 \mathrm{p}$.

Recebido em: 28/07/2014 Aceito em: 17/05/2016 